\title{
Jute Composites as Wood Substitute
}

\author{
Debiprasad Gon ${ }^{1, *}$, Kousik Das ${ }^{2}$, Palash Paul ${ }^{2}$, Subhankar Maity ${ }^{2}$ \\ ${ }^{1}$ Indian Jute Industries’ Research Association, 17, Taratala Road, Kolkata-88 \\ ${ }^{2}$ Panipat Institute of Engineering, Technology , Samalkha, Panipat, Hary ana
}

\begin{abstract}
Jute fibre is a promising reinforcement for use in composites on account of its low cost, low density, high specific strength and modulus, no health risk, easy availability, renewability and much lower energy requirement for processing. In recent years, there has been an increasing interest in finding new applications for jute fibre reinforced composites that are traditionally used for making ropes, bags, hessians, sacking, mats, and carpet.To protect environment, consumptions of wood should be reduced that will increase number of tree in the world which can maintain the balance in nature. A major portion of woods are used for making home furniture, household products and building and constructions. In all these cases wood can be replaced by composite materials made from natural fibres like jute, coir, sisal etc.Jute fibre composites enjoy excellent potential as wood substitutes in view of their low cost, easy availability, saving in energy and pollution free production. In order to improve upon the laboratory-industry linkages towards application development \& commercialization, some advanced composites mission launched on jute composites such as 'Jute-Coir Composites Boards', 'Jute-glass composite components for railway coaches' and others.The use of jute fiber mats in combination with polymer films potentially offers a rapid and simple means of manufacturing composites through film stacking, heating and press-consolidation.
\end{abstract}

Keywords Jute Fibre, Jute Composite, Wood, Natural Fibre, Composites

\section{Introduction}

Natural fibre reinforced composites have a good potential as a substitute for wood-based material in many applications. The development of environ ment-friendly green materials is because of natural fiber's biodegradability, light weight, low cost, high specific strength compared to glass and carbon, recycling and renewing natural sources. Composites, the wonder material with light-weight, high strength-to-weight ratio and stiffness properties have come a long way in replacing the conventional materials like metals, woods etc. The material scientists all over the world focused their attention on natural composites reinforced with jute, sisal, coir, pineapple etc. primarily to cut down the cost of raw materials. The jute fibre is an important bast fibre and comprises bundled ultimate cells, each containing spirally oriented micro - fibrils bound together.

From the point of view of wood substitution, jute composites could be an ideal solution. With ever depleting forest reserves, a composite based on renewable resources is poised to penetrate the market. Indigenous wood supply for plywood industry having been stopped virtually and with increasing landed cost of imported plywood veneers, the jute

* Corresponding author:

debiprasadgon@gmail.com (Debiprasad Gon)

Published online at http://journal.sapub.org/textile

Copyright (C) 2012 Scientific \& Academic Publishing. All Rights Reserved composite boards offer very good value for the customers without any compro mise in properties.

The jute-coir boards proving superior over application plywood boards find potential in railway coaches for sleeper berth backing, for building interiors, doors \& windows besides in transportation sector as backings for seat \& backrest in buses. Typical jute composites boards do not prove well on the grounds due to its moisture absorption \& screw holding strength. Detailed evaluation of the jute-coir board samples has been carried out for their applications as berth backings \& partitions in railway coaches; the results conform to the railways' requirements.

The use of jute fiber mats in combination with polymer films potentially offers a rapid and simple means of manufacturing composites through film stacking, heating and press-consolidation

\section{Definitions}

\subsection{Composites[1]}

A composite material is one in which two or more materials that are different (structure, properties) are combined to form a single structure with identifiable interfaces at multi-scales to achieve properties that are superior to those of its constituents. In general, composites can be defined as a select combination of dissimilar material formed with a specific internal structure and with a specific 
external shape or form. Composites are designed to achieve unique mechanical properties and superior performance characteristics not possible with any of the component material a lone.

\subsection{Textile Composites [1]}

Textile composite materials are composed of fibres fibre, yarn or fabric system and matrix material that is bind and protect the fibres. The fibres are usually the load bearing members, while the polymeric matrix provides transverse integrity and transfers the load onto the fibres. Besides of the properties of two main components of fibre and matrix, the fibre/matrix interphase also plays a crucial role for the load transfer. It is not a distinct phase, as the interphase does not have a clear boundary. This region exits between bulk fib re and bulk matrix and may contain several different layers as in the case of sizing.

\subsection{Jute Composites[2]}

Jute composite materials consist of jute fibres of high strength and modulus embedded in or bonded to a matrix with distinct interfaces (boundary) between them. In this form, both fibres and matrix retain their physical and chemical identities, yet they produce a combination of properties that can not be achieved with either of the constituents acting alone. In general, jute fibres are the principle load carrying member, while the surrounding matrix keeps them in the desired location and orientation, acts as a load transfer medium between them, and protects them from environmental damages due to elevated temperature and humidity.

\section{Properties of Wood}

Timber as felled has considerable mo isture content[MC] present as 'free' mo isture within the cell cavities and 'bound' or 'co mbined' mo isture saturating the cell walls. The freshly sawn lumber will lose perhaps $50 \%$ of its total weight, shrink somewhat and become much stronger, harder and more durable during the seasoning[drying and stabilizing] process. The seasoning process also improves timber workability and the bonding of adhesives and surface finishes. The target MC for the process is normally $12 \%$ (i.e. weight of water compared to weight of totally dry wood) but it may vary between $10 \%$ and $15 \%$ in moderate climate conditions; at these levels only bound moisture remains. Timber with MC between $15 \%$ and $25 \%$ is sometimes regarded as partially seasoned. The tangential shrinkage is only about $3.5 \%$ and the radial shrinkage is around $2.5 \%$. The specific gravity of the cell wall material is about the same in most timbers is about 1.50 .

\subsection{Density Classification[3]}

The density of seasoned timber is usually measured for classification purposes - at $12 \%$ air-d ry MC.

- exceptionally light — under $300 \mathrm{~kg} / \mathrm{m}^{3}$

- light - 300 to $450 \mathrm{~kg} / \mathrm{m}^{3}$

- medium- 450 to $650 \mathrm{~kg} / \mathrm{m}^{3}$

- heavy — 650 to $800 \mathrm{~kg} / \mathrm{m}^{3}$

- very heavy - 800 to above $\mathrm{kg} / \mathrm{m}^{3}$

Wood is composed of cellulose, lignin, ash-forming minerals, and extractives formed into a cellular structure. (Extractives are substances that can be removed from wood by extraction with such solvents as water, alcohol, acetone, benzene, and ether.) Variations in the characteristics and volumes of the four components and differences in the cellular structure result in some woods being heavy and some light, some stiff and some flexible, and some hard and some soft.

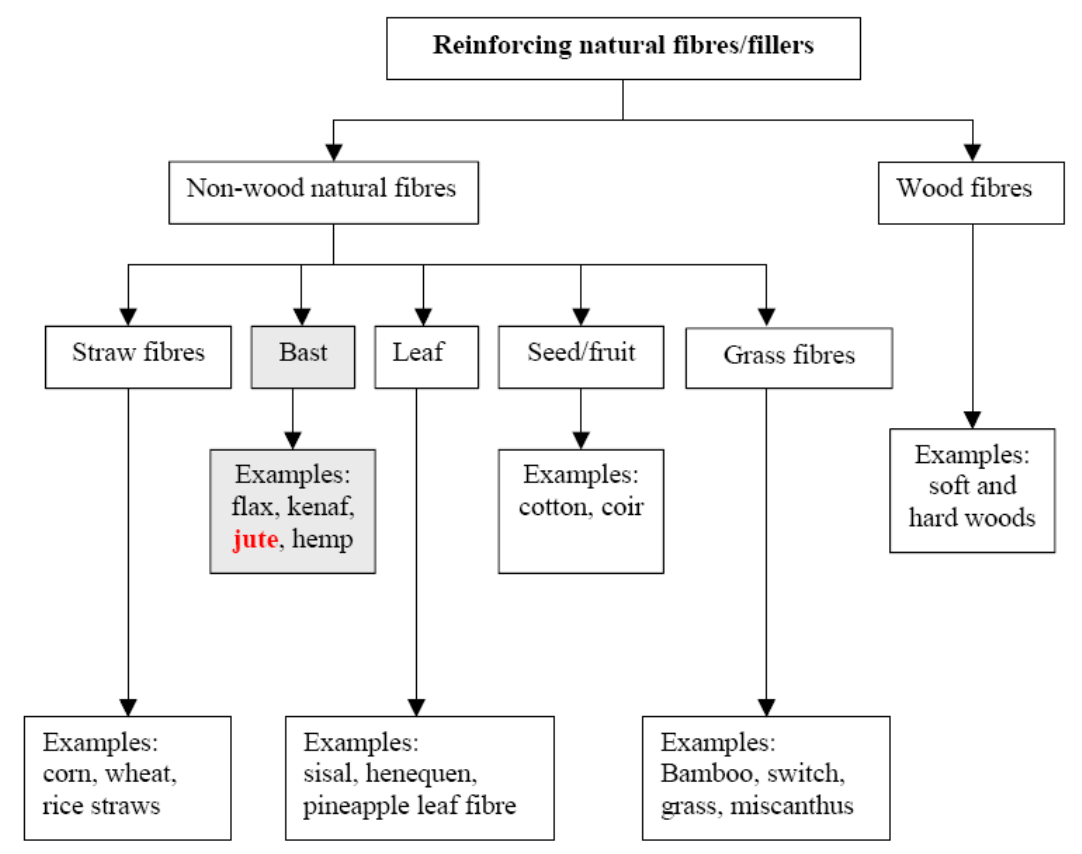

Figure 1. Classification of natural fibres which can be used as reinforcement or fillers in polymers [4] 


\section{Why Jute Fibre?}

The most important types of natural fibres used in composite materials are flax, hemp, jute, kenaf, and sisal due to their properties and availability. Using jute fiber for composites has many advantages. Firstly is has wood like characteristics as it is a bast fibre. Jute has high specific properties, low density, less abrasive behaviour to the processing equipment, good dimensional stability and harmlessness. Jute is renewable, versatile, nonabrasive, porous, hydroscopic, visco-elastic, biodegradable, combustible, and reactive. The fiber has a high aspect ratio, high strength to weight ratio, and has good insulation properties. Jute textile is a low cost eco-friendly product and is abundantly available, easy to transport. The biodegradable and low priced jute products merge with the soil after using providing nourishment to the soil. Being made of cellulose, on combustion, jute does not generate toxic gases. Some might consider part of these properties as disadvantages, such as biodegradable and combustible, but these features provide a means of predictable and programmable disposal not easily achieved with other resources.

\subsection{Strength of Jute as Reinforcing Material for Composite[5]}

- Jute is bio-degradable and replenishes earth nutrients.

- J Jute posses no threat to the environment because it neither emits toxic gases nor harmful chemicals.

- J Jute will not cause the problems like the synthetic material in waste management cycles through emitting hazardous gas es during incineration of landfill sites.

- J Jute makes durable and strong composite, handling of which is easier.

- J Abundant availability of jute fibre.

\subsection{Weakness of Jute as Reinforcing Material for Composite[5]}

- J Moist condition, usually more than $60 \%$ of moisture can reduce the tensile strength of the Jute Fibre.

- J Acidic contact or atmosphere can reduce the luster as well as tensile strength.

- J Pectin and lignin bonds inherited in Raw Jute can rot or deteorate the quality of the Jute Fibre. However, this weakness can be overcome by proper retting, washing, drying process and modification of jute fibre.

\subsection{Use of Jute Plant for Making Composites as Wood Substitute[4]}

The scheme shown below gives possible processing pathways that lead to the composite products that can come from each fraction of the jute plant. The entire plant (leaves, stock, pith, roots) can be used directly to produce structural and non-structural composites and can be used in combination with thermoplastics to produce pellets that can be extruded into a wide variety of products. By using the entire plant, processes such as retting, fiber separation, fraction purification, etc. can be eliminated which increases the total yield of plant material and reduces the costs associated with fraction isolation. The plant can be fractionated into fiber types and each type utilized for different composites. By utilizing the by-product from the long fiber isolation process, for example, the overall cost of long fiber utilization is reduced.

\section{Jute Fibre[6]}

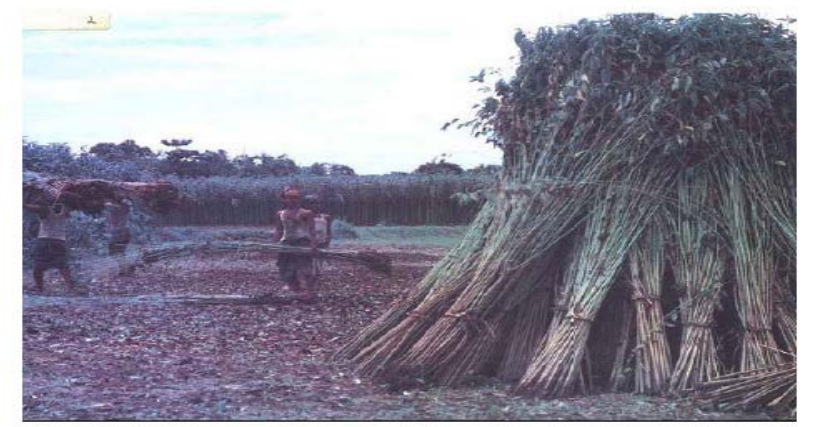

Figure 2. Harvest of jute plants[6]

Jute is multicelled in structure (Fig. 3). The cell wall of a fibre is made up of a number of layers: the primary wall and the secondary wall (S), which again is made up of the three layers (S1, S2 and S3). As in all lignocellulosic fibres, these layers mainly contain cellulose, hemicellu lose and lignin in varying amounts. The individual fibres are bonded together by a lignin-rich region known as the middle lamella. Cellu lose attains highest concentration in the S2 layer (about $50 \%$ ) and lignin is most concentrated in the middle lamella (about 90\%) which, in principle, is free of cellulose. The S2 layer is usually by far the thickest layer and dominates the properties of the fibres. Cellulose, a primary component of the fibre, is a linear condensation polymer consisting of Danhydro- glucopyranose units joined together by $\beta-1$, 4-glucosidic bonds. The long chains of cellulose are linked together in bundles called micro-fibrils (Fig. 3).

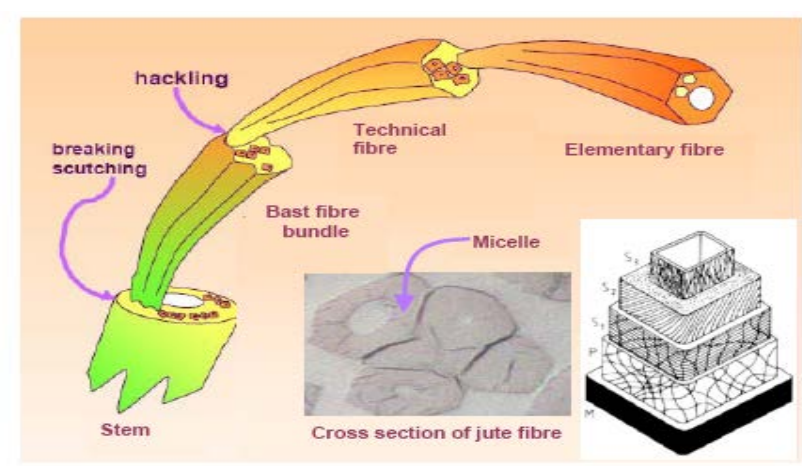

Figure 3. Jute fibre structure[7]

Hemicelluloses are also found in all plant fibres. Hemicelluloses are polysaccharides bonded together in relatively short, branching chains. They are intimately associated with the cellulose microfibrils, embedding the cellulose in a matrix. Hemicelluloses are very hydrophilic 
and have lower molecular masses than both cellulose and lignin. The degree of poly merization (DP) is about $50-200$. The two main types of hemicelluloses are xylans and glucomannans. Lignin is a randomly branched polyphenol, made up of phenylpropane (C9) units. It is the most complex polymer among naturally occurring high-molecular-weight materials with an amorphous structure. Of the three main constituents in fibres, lignin is expected to be the one with least affinity for water. Another important feature of lignin is that it is thermoplastic (i.e., at temperatures around $90^{\circ} \mathrm{C}$ it starts to soften and at temperatures around $170^{\circ} \mathrm{C}$ it starts to flow).

Table 1. Chemical composition of jute fibre[7]

\begin{tabular}{|c|c|}
\hline Constituents & $\%$ \\
\hline Cellulose & $60-62$ \\
\hline Hemi Cellulose & $22-24$ \\
\hline Lignin & $12-14$ \\
\hline Others & $1-2$ \\
\hline
\end{tabular}

Table 2. Properties of jute fibre in comparison with other fibres[7]

\begin{tabular}{|c|c|c|c|c|}
\hline Fibre & $\begin{array}{l}\text { Density } \\
\left(\mathrm{g} / \mathbf{c m}^{3}\right)\end{array}$ & $\begin{array}{l}\text { Young's } \\
\text { modulus } \\
\text { (GPa) }\end{array}$ & $\begin{array}{c}\text { Tensile } \\
\text { strength } \\
\text { (MPa) }\end{array}$ & $\begin{array}{c}\text { Elongation } \\
\text { at break } \\
(\%)\end{array}$ \\
\hline Jute & 1.3 & 26.5 & 393-773 & $1.5-1.8$ \\
\hline Cotton & $1.5-1.6$ & $5.5-12.6$ & $287-597$ & $7-8$ \\
\hline Flax & 1.5 & $27.6-46.9$ & $345-1035$ & $2.7-3.2$ \\
\hline Ramie & - & 61.4-128 & $400-983$ & $3.6-3.8$ \\
\hline Sisal & 1.5 & $9.4-22$ & $511-635$ & $2-2.5$ \\
\hline $\begin{array}{c}\text { Viscose } \\
\text { (cord) }\end{array}$ & - & 11.0 & 593 & 11.4 \\
\hline Softwood & 1.5 & $18-40$ & 1000 & - \\
\hline Hardwood & 1.2 & 37.9 & - & - \\
\hline E-glass & 2.5 & 70 & $2000-3500$ & 2.5 \\
\hline S-glass & 2.5 & 86 & 4570 & 2.8 \\
\hline Aramid & 1.4 & $63-67$ & $3000-3150$ & $3.3-3.7$ \\
\hline Carbon & 1.4 & $230-240$ & 4000 & 1.4-1.8 \\
\hline
\end{tabular}

The jute fibre possesses moderately high specific strength and stiffness. Therefore, it is suitable as reinforcement in a polymeric resin matrix. However, it exhibits considerable variation in diameter along with the length of individual filaments. The properties of the fibre depend on factors such as size, maturity and processing methods adopted for the extraction of the fibre. Properties such as density, electrical resistivity, ultimate tensile strength and initial modulus are related to the internal structure and chemical composition of fibre.

\section{Some Application of Jute Composite as Wood Substitute}

\subsection{Jute mat[8]}

Jute mat is an example of a non-woven jute fibre composite. The material is composed of jute fibre, resin and a small amount of synthetic fibre. The manufacturing process creates a mat that can be then be molded into creative shapes, such as a car door panel. The result is a light but strong component.
Uses: - Manufacturers might consider using a jute fibre composite mat for products that require the characteristics of wood, but have a shape that cannot be made with a standard wood product. Manufacturers can use the mats in their molding process. Heat and pressure will set the lignin and resins in the mat, resulting in a hard, lightweight shape.

Typical products made using jute fibre composite are molded door skins, automotive interior trim and architectural moldings. The mat itself (before any molding process) has also been used gardening products to hold seeds in place, prevent weeds and add slow release fertilizer to seedlings.

\subsection{Jute Fibre-Thermoplastic Composites}

Wood flour is used as filler with thermoplastics. The resulting mixture can be used in injection molding or compression molding processes. Clothes hangers and almost any molded plastic objects can be made from th is product.

\subsection{Building \& Construction[9]}

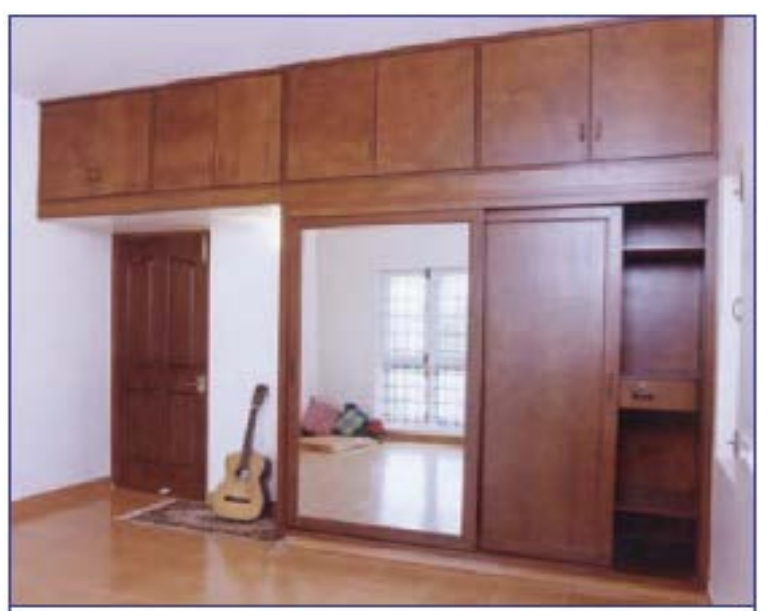

Figure 4. Jute-coir Composite Boards

Building \& construction technology trends worldwide establish the fact that the composites occupy a prominent position as the building material dislodging many conventional ones. Composites are an attractive proposition considering the embedded energy especially against metals. Other important properties such as impact resistance, corrosion resistance, thermal \& acoustic insulation all contribute favourably to composite claiming its position as an ideal building material.

A wide array of innovative composite products suitable for building \& construction sector and bio-medical appliances had been developed by the Advanced Composites Programme. Jute-coir composite boards, FRP sandwiched door shutters, FRP toilet blocks etc. developed under its various projects address the crucial need of the hour 'post-disaster relief' at the quickest possible time!

The project aims at developing an oriented jute face layer (veneer) for coir plyboard. Natural hard fibres such as coir and jute impregnated with phenolic resins are used for its manufacture. The project activities will enable the production of coir plyboards with proper orientation of jute 
having a very similar appearance of wood. Moreover, products with consistent standard can be offered to the market by ascertaining the quality of boards by proper testing facilities.

Natural hard fibres such as coir and jute imp regnated with phenolic resins were used for manufacturing these boards. A very thin layer of jute fibres impregnated with phenolic resin was overlayed as face veneer for improved aesthetics and to give a wood like smoother finish.

Jute-coir composite boards, impregnated with phenolic resin, are termite \& borer resistant and also inherently fire retardant. These boards with excellent insulation properties provide considerable differential between ambience and internal room temperature. The sheds would require nominal ma intenance such as yearly painting on external surfaces

\subsection{Composite Doors \& Door Frames[9]}

The doors made of jute-FRP skins, sandwiched with core materials such as rigid polyurethane foam, expanded polystyrene; paper honeycomb etc. can have potential usage in residential buildings, offices, schools, hospitals, laboratories etc. The doors made by FRP-PUF sandwich composites offer special advantages compared to those manufactured from traditional monolithic materials such as wood \& metals. The principal fabrication technique employed is contact moulding. Wooden The PU foam is sandwiched between the sheets by in-situ foaming process followed by painting \& polishing. Proper usage of additives imparts fire retardant properties to the doors. FRP doors conforms to BIS specifications (IS: 4020). Some of the unique features of FRP doors are:

\begin{tabular}{|c|c|}
\hline Water proof & Corrosion resistance \\
\hline Fire retardant & Termite resistance \\
\hline Functional superiority & Design flexibility \\
\hline \multicolumn{2}{|c|}{ Attractive design \& in-built colour shades etc. } \\
\hline
\end{tabular}

A cost \& weight analysis of FRP doors vs. conventional wooden doors revealed that replacing sal wood door with FRP door could result in cost \& weight savings of $40 \%$ \& $60 \%$ respectively

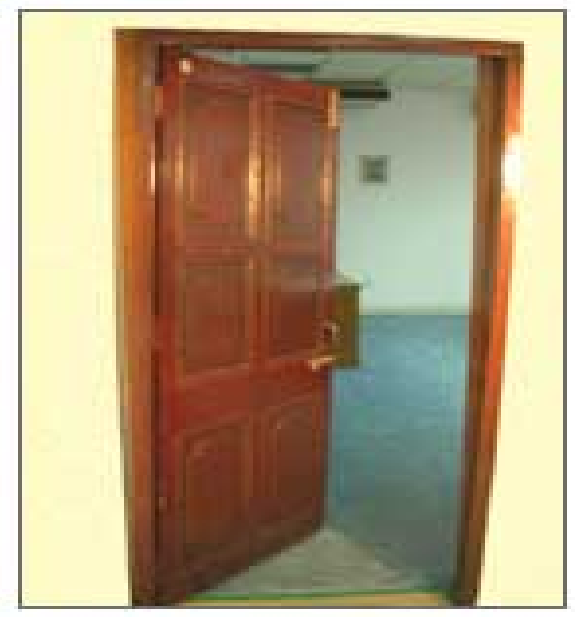

Figure 5. Jute composite door
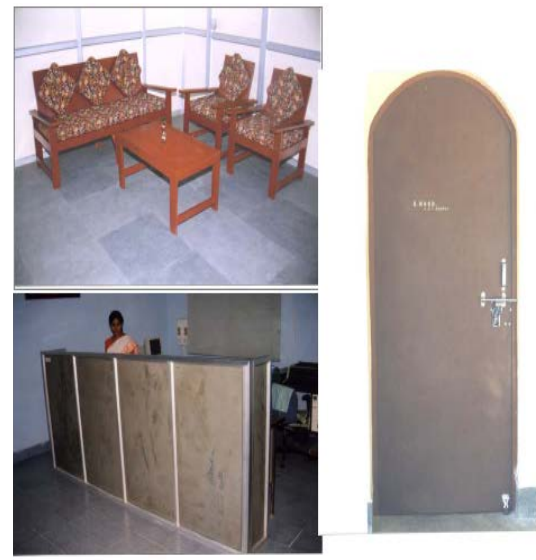

Figure 6. Jute composite furniture

\subsection{Fishing B oats [9]}

On a preliminary post-tsunami survey on the extent of damage caused in the coastal Tamil Nadu alone, it was revealed that around 7000 mechanized diesel powered fishing boats \& trawlers of lengths varying between $10-20 \mathrm{~m}$ were lost. Further, over 30,000 manual \& motorized boats were lost in the calamity. Most of such boats were made of wood \& steel. Wood/steel is highly prone to decay in the saline environment and thus the boats require frequent maintenance.

Due to their imp roved impact resistance, flexural strength and corrosion resistance properties, composite boats can withstand severe slamming by tidal waves and they do not get badly destroyed like the wooden ones. The composite boat lasts for 12-15 years as compared to merely 3 years of service life for wooden ones. In the event of such unforeseen calamities like tsunami, it is possible to repair \& reuse most of them.

The catamaran type fishing boats are very popular among the fishermen from south-eastern coast of India. Catamarans are flat-bottomed boats, which make themhydrodynamically more stable compared to single hull boat, particularly at high seas. Flat-bottomed hull profile makes them suitable even for low draft sailing. The catamaran type hull is subjected to less drag and thus requires less energy for boat propulsion.

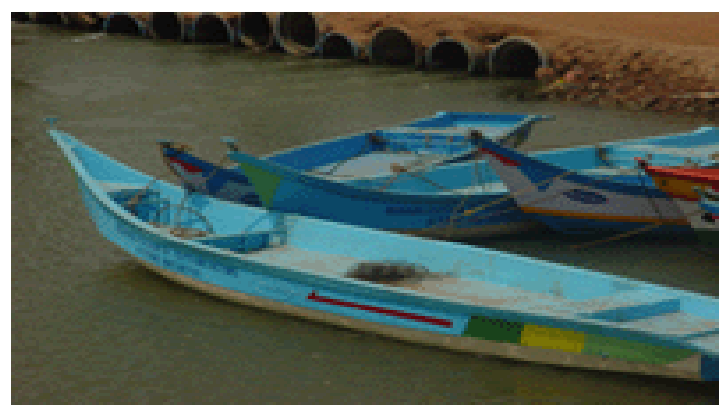

Figure 7. Jut e composite boat with outer coating

\subsection{Natural Fibre Board}

The critical advantages of natural fib re based boards are as follows :

- Termite/borer Proof 
- Good insulation properties

- Fire retardant

- Water resistant

- Strong \& rigid

- Can be nailed, screwed, laminated and cut sharply.

The characteristics of natural fibre composite boards are :

v attractive natural looks

v it can be painted, polished or laminated

vater proof with minimum surface absorption

$\checkmark$ economical

v strong and rigid

v environment friendly

v can be nailed, screwed and cut sharply.

Some of the applications of these natural fibre based boards are as follows :

- Partitioning

- False ceiling \& roofing

- Surface panelling

- Furniture

- Cupboards, wardrobes etc.

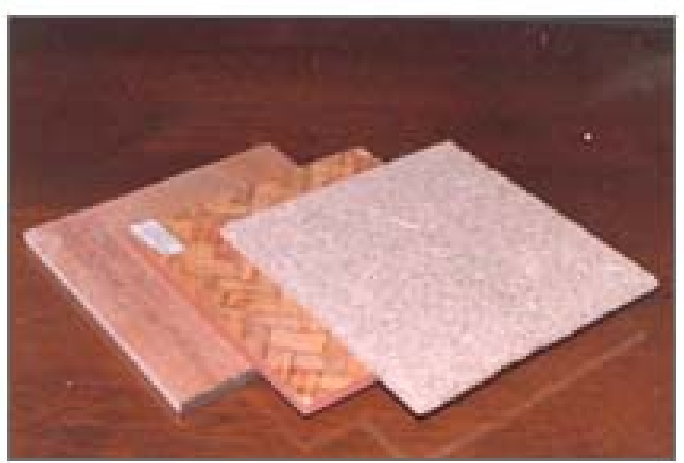

Figure 8. Particle Board

\section{Fabrications of Jute Composites[10, $11,12,13]$}

Phenolic resins is one of the first synthetic resin exploited commercially for fabrication of jute-composite products mainly because of its high heat resistance, low smoke emissions, excellent fire retardance properties and compatibility with jute fibres. Phenol-formaldehyde based jute composites products have been used for quite so metimes as wood \& ceramic substitutes. Today, where costs \& performance have a high impact on economics, phenolic resins has been accepted in many high performance applications for composites. Compression moulding of composites based on jute-phenolic system has been commonly practised since a few decades. In this process, jute is impregnated with the phenolic resin by spraying process followed by drying under hot air dryer. These pre-imp regnated jute layers are arranged together for desired thickness and compression moulded at high pressure of $700-800 \mathrm{~kg} / \mathrm{m}^{2}$ and at temperature of around $120-140^{\circ} \mathrm{C}$.

Usually for moulded jute composites with polyester resin, the resin intake can be maximum up to $40 \%$. Both hot press moulding and hand lay-up technique can be used for its fabrication. In the latter process, the resin take up may go up to $300-400 \%$ of jute fibre used, which is not economical. Also, it is seen that some pre-processing of jute/treatment of fibre is required so that the interface problem could be solved. Generally, when unsaturated polyester resin is used with glass fibre, the ratio maintained is $2.5: 1$. Whereas, for resin with jute, the ratio maintained is 3.5-4:1. However, an increase in temperature increases the productivity. Even with unsaturated polyester resin, hot condition impregnation is usually done for higher p roductivity.

Hybrid composite of glass and jute fibre can be fabricated initially by the hand lay-up technique for making the sheet-moulding compound and subsequently by using a compression-moulding machine. 10-ply hybrid laminates containing 8 inner plies of untreated/silane/ titanate/TDI treated jute fibre sandwiched between two outer plies of glass fibre (weight content of jute : $25-27 \%$ ) can be made by the aforesaid process. Curing is done at $80{ }^{\circ} \mathrm{C}$ under a pressure of approx. $2 \times 10^{5} \mathrm{~N} / \mathrm{m}^{2}$ for $90 \mathrm{~min}$.

Pultrusion is another unique process that converts primary raw materials directly into finished products, continuously and automatically, utilizing most of thermoset/thermoplastic resins. Jute, available in continuous forms such as mat, roving, tapes, yarn etc., is impregnated with resin \& passed through hot die to cure the product. The speed of pultrusion ranges from $0.4-1.0 \mathrm{~m} / \mathrm{min}$ depending on the complexity of the products. The loading of jute is anywhere between 50-70\%. Pultruded jute composites have good electrical insulation, corrosion \& high fire retardance properties. They find applications in roofing sheets, cable trays, doors \& window frames, paneling, sections for wardrobe, partitions, etc.

Resin Transfer Moulding (RTM) is a quick and cost effective process for the production of quality volume composites. Jute based reinforcement using combinations of woven fabric and non-woven needle punched felt forms have been used successfully in the moulding various complex shapes.

\section{Disadvantages of Jute Composites}

The jute fibre composites possess also some disadvantages. The main disadvantage is the poor compatibility between a hydrophobic poly mer matrix and the hydrophilic fibres. This leads to the formation of weak interfaces, which result in poor mechanical properties of the composites. Other important disadvantages of the natural fibre composites are the high sensitivity of natural fibres towards water and the relatively poor thermal stability. Water absorption on composites is an issue to be considered since the water absorbed by the fibres in the composite could lead to swelling and dimensional instability and to a loss of mechanical properties due to the degradation of the fibres and the interface between the fibre and matrix. 

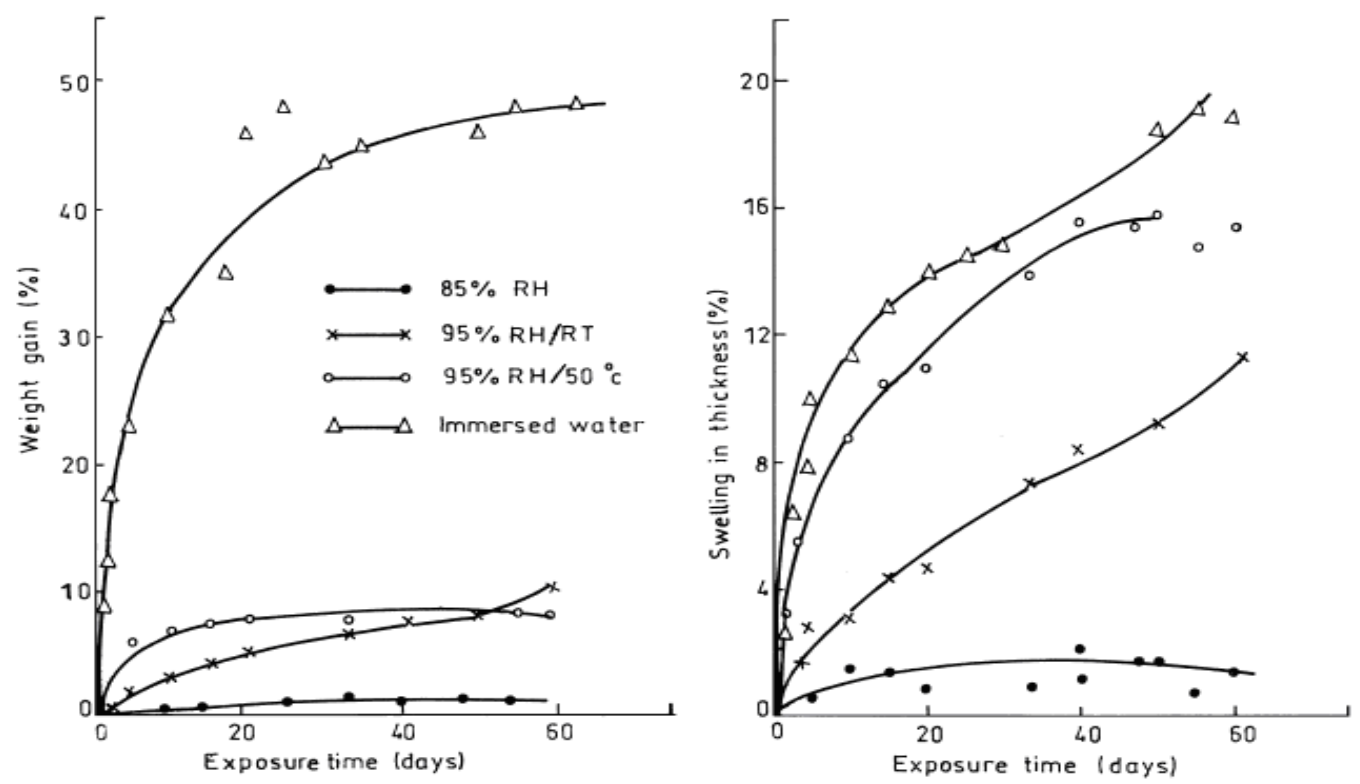

Figure 9. Weight gain and swelling in thickness of jute composites at different humidity level

\subsection{Effect of Humi dity on Jute Reinforced Composite[14]}

\subsubsection{Thickness and Weights[14]}

Figs below show the dimensional change of jute composites as a function of exposure time under different humid ity. Increasing humidity levels, increases weight gain and thickness swelling of samples as expected. At 95\% RH and $95 \% \mathrm{RH} / 50^{\circ} \mathrm{C}$, mo isture-induced effects resulted in a weight gain of $6 \pm 8 \%$ while thic kness swelling remains up to $8 \pm 10 \%$ near saturation.

\subsubsection{Tensile and Flexural Strength[14]}

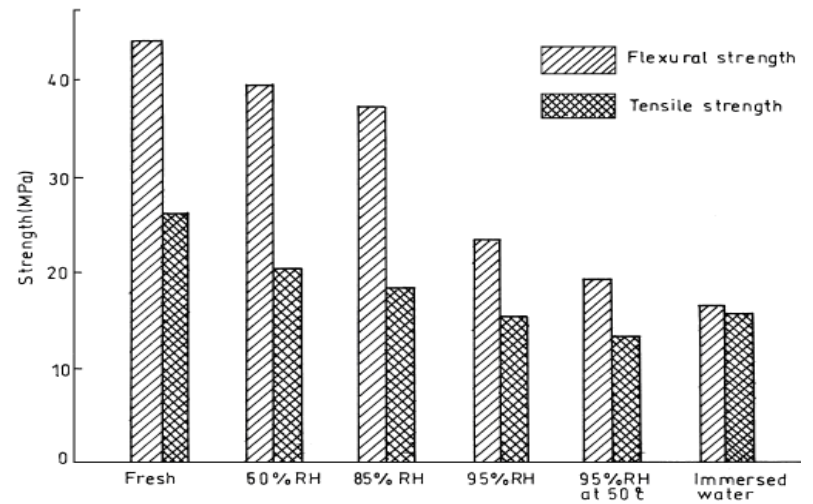

Figure 10. Effect of humid conditions on the tensile and flexural strength of jute composites

The tensile strength and flexural strength of jute composites exposed to various humidity were shown in fig 10. The reduction in strength with the increasing humidity levels is expected to depend on the a mount of moisture/water which disturbs the mechanical integrity of the composites by affecting the fibres, the matrix and the fibre-matrix interface simultaneously. It was found that the tensile strength of composites under hygrothermal condition was more affected than the composites immersed in water, probably due to the plasticization effects. On the other hand, the flexural strength was found to be more affected under immersed water than those at $95 \% \mathrm{RH}$ at $50^{\circ} \mathrm{C}$.

\subsubsection{Biological Defacement[14]}

Biological defacement study of jute composites was undertaken to assess the behaviour in humid/wet environment in view of the increasing health incident of fungal infestation. It was found that the intensity of blackish spots on the surface of samples increases with increasing humidity levels. The composites exposed at $60 \% \mathrm{RH}$ and $95 \% \mathrm{RH}$ at $50^{\circ} \mathrm{C}$ remained virtually unaffected as compared to the control sample. On the contrary, a slight appearance of localized black spots on the surface was initiated at $85 \% \mathrm{RH}$ and grew significantly at 95\% RH and immersed water conditions. The intensified fungal growth at the cut edge as well as on the surface of samples was noticed under immersion in water. The intensity and spreading of these growths over the surface depend on moisture vapour transmission from the surface. In order to obtain a detailed view of black spots, SEM observation reveals a large number of white patches.

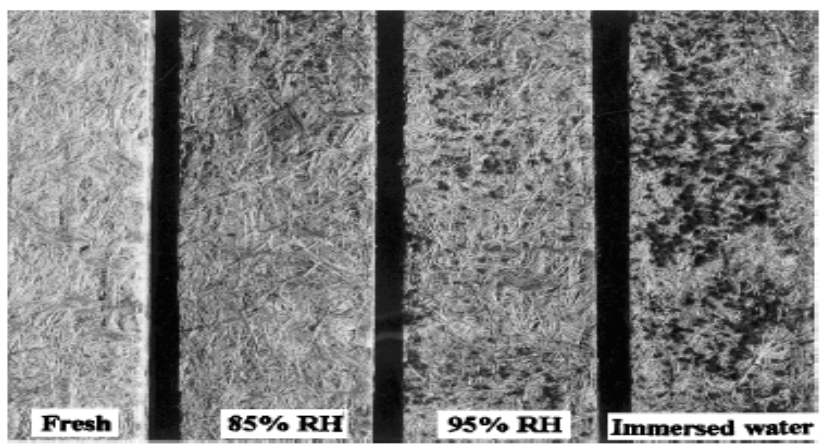

Figure 11. Jute composites showing blackish spots on the surface at different humidity levels

\subsubsection{Effect of Weathering[15]}



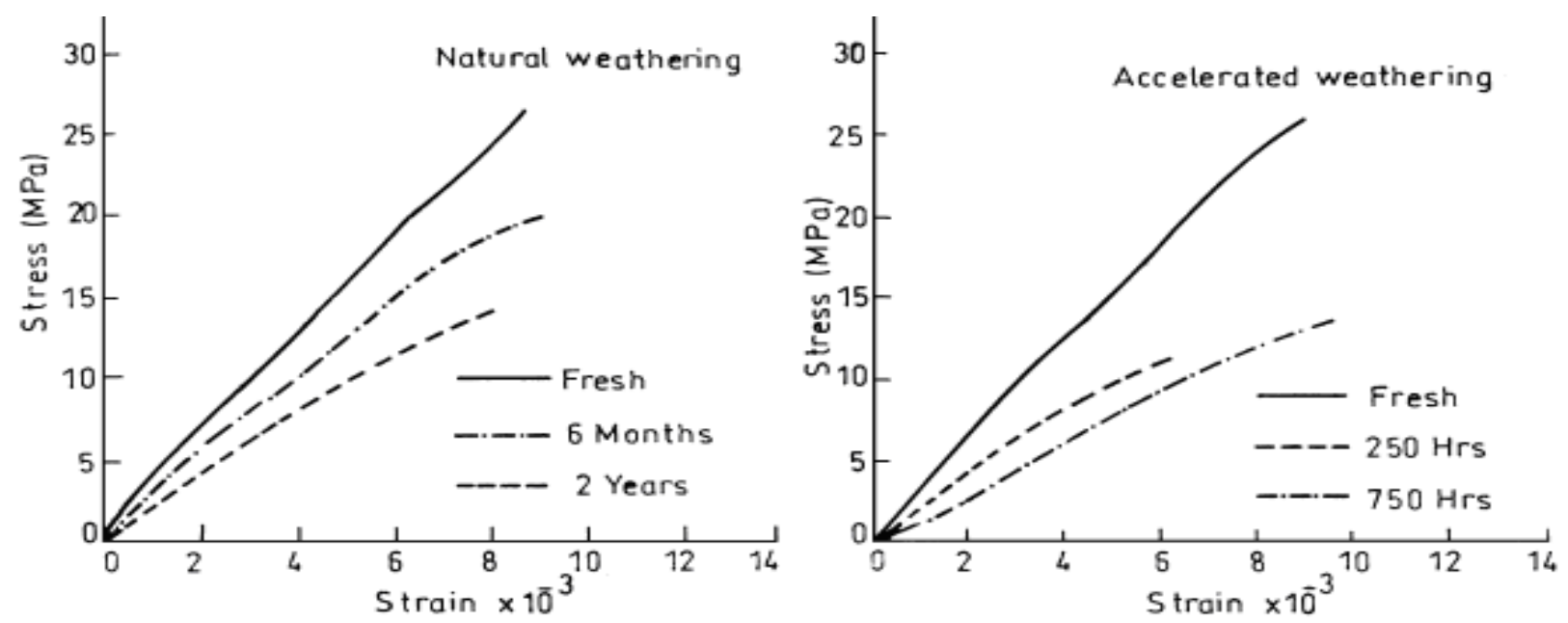

Figure 12. Tensile stress-strain curves of jute composites exposed to nat ural and accelerated weathering conditions

One early effect of weathering noted was the appearance of a milky colour on the surface of composites. The colour fading continues as the exposure proceeds in both natural and accelerated weathering. The deterioration of composites was initiated by the fibre ridging followed by the resin film rupture through cracking and then the fibre pop-out. This is attributed main ly due to stresses produced by the differential swelling and shrinkage of the fibre/resin caused by changes in moisture content, and also stresses built up at the interface due to a large variation in the coefficient of thermal expansion of resin and fibre leading, to the failure of fibre/resin bond. Increasing exposure outdoors, the initiation of frag mentation in jute occurred due to degradation of the lignin portion of fibres by UV attack

\subsubsection{Effect of Mo isture on Jute Fibres[16]}

There is, however, a major drawback associated with the application of jute fibres for reinforcement of resin matrices. Due to presence of hydro xy and other polar groups in various constituents of jute fibre, the moisture uptake is high (approx. $12.5 \%$ at $65 \%$ relative humidity $\& 20^{\circ} \mathrm{C}$ ) by dry fibre. All this leads to

(i) poor wettability with resin and

(ii) weak interfacial bonding between jute fibre and the relatively more hydrophobic matrices.

Environmental performance of such composites is generally poor due to delamination under humid conditions. With increase in relative humidity upto $70 \%$, the tenacity and Young's modulus of jute increases but beyond $70 \%$, a decrease is observed. Thus, it is essential to pre-treat the jute fibre so that its moisture absorption is reduced and the wettability by the resin is improved.

\section{Innovations}

\subsection{Improvement As pects}

A composite has three entities that are susceptible to failure - the reinforcement, the matrix and the interface. The failure of one can initiate failure of the others, and the actual process that takes place in any particular case is determined by the stress required to activate each individual mechanism. The mechanism activated by the lowest stress will normally govern composite failure.

Thus, In order to increase the potential application area of jute fibres as reinforcement in composites, it is necessary to concentrate more on three major aspects
(a) Fibre modification
(b) Resin matrix
(c) Coupling agents.

\subsection{Modification of J ute Fibre[8]}

Therefore, to improve the adhesion between the matrix and the fibres, a third component, called compatibiliser, has to be used for matrix modification or the fibres have to be surface modified prior to the preparation of the composites. Several studies have shown the influence of various types of chemical modifications on the performance of natural fibres and fibre reinforced composites. The different surface chemical modifications of natural fibres such as alkali treatment, silane treatment, isocyanate treatment, latex coating, permanganate treatment, acetylation, monomer grafting under UV radiation, etc. have achieved various levels of success in improving fibre strength and fibre/matrix adhesion in natural fibre composites.

In order to develop composites with better mechanical properties and environmental performance, it is necessary to impart hydrophobicity to the fibres by chemical reaction with suitable coupling agents or by coating with appropriate resins. Such surface modification of jute fibre would not only decrease moisture adsorption, but would also concomitantly increase wettability of fibres with resin and improve the interfacial bond strength, which are critical factors for obtaining better mechanical properties of composites. The modification is required to improve the wettability and compatibility of the fibre with resin matrix to produce strong fibre-matrix interface. Modification can be done in three different ways: 


\subsubsection{Physical Modification}

Different physical treatments like boiling of fibre with or without pressure, plasma treatment etc can improve the cleaning of fibre surface which can react with resin easily to form a strong interface. Poly meric coatings of jute fibre with phenol-formaldehyde or resorcinol formaldehyde resins by different approaches are highly effective in enhancing the reinforcing character of jute fibre, giving as high as $20-40 \%$ improvements in flexural strength and 40-60\% improvements in flexural modulus. These modifications improve the fibre-matrix resin wettability and lead to improved bonding.

\subsubsection{Chemical Modification[17]}

The chemical modification involves mainly etherification, etherification, cyanoethylation, grafting etc. All these chemical reactions involve mainly the hydroxyl groups of the fibre and the modified fibre develops certain characteristics like low moisture regain, improved compatibility with resin etc. Jute is chemically treated with isopropyl triis ostearoyl titanate (abbreviated as titanate), g aminopropyl trimethoxy silane (abbreviated as silane), sebacoyl chloride (SC), and toluene diisocynate (TDI). All these reagents are expected to block the hydroxy groups of jute thus making the fibres more hydrophobic.

\subsubsection{Graft Copolymerisation}

Jute can be graft copolymerised with vinyl monomers such as methyl methacrylate, ethyl acrylate, styrene, vinyl acetate, acrylonitrile and acrylamide in the presence of different redox initiator systems such as vanadium cyclohexanol, vanadium - cyclohexanone, etc. Grafting of polyacrylonitrile (10-25\%) imparts $10-30 \%$ improvements in flexural strength and flexural modulus of the composites. Grafting of polymethylmethacrylate is also effective in this respect, though to a lower degree.

\subsubsection{Bio-Chemical Modification}

Grey jute fibre contains some natural as well as added impurities, which needs to be cleaned for making jute fibre suitable for composite preparation. Moreover, removal of some amount of hemicelluloses as well as lignin makes the fibre more suitable for its compatibility with resin, which ultimately results in better jute reinforced products. Several processes have been tried on jute fibre, which include scouring, bleaching, enzyme treatment, alkali treatment, thermo-hydrolysis etc. to improve its adhesion with resin. These modification processes also lead to some reduction in its tensile property but if the treatments are carried out at optimum conditions the composites produced shows improved tensile as well as flexural behaviour

\subsection{Coupling Agents}

The adhesion is poor at the interface between jute fibre and non-polar polymer matrix, which is provided only by van der Waals forces due to the lack of reactive groups in the molecule of the polymers. The coupling agent is able to act as a compatibiliser for polar natural fibre and non-polar polymer matrix systems.

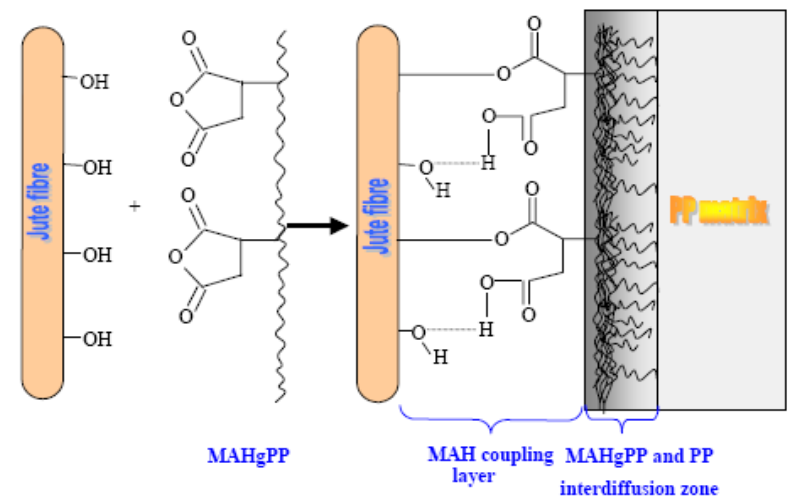

Figure 13. Hypothetical structure of MAHgPP coupling agent and jute fibre at the interface

\section{Conclusions}

From the point of view of wood substitution, natural fibre composites would enjoy wider acceptance. India enjoys a niche for the natural fibre composites as the country is endowed with large varieties of natural fibres such as jute, coir, sisal, pine needles etc. Thus, the usage of natural fibre based products in post-disaster management of rehabilitation \& rebuilding would become cost competitive compared to other building materials. Environmental concerns and increasing competition are forcing to think about optimizing the wood resource and maximizing performance as opposed to the old focus on price. The natural fibre based composite products are good example of such an optimization strategy. Use of jute based composites increases its overall utilization of the wood resource. These products are a result of research into product development and process technology. Efficiency and innovation are keys to maintaining a competitive edge in the global markets of today and tomorrow.

With ever depleting forest reserves and corresponding premium on wood, a composite based on renewable resources such as jute, coir, sisal etc. is poised to penetrate the market. Indigenous wood supply for plywood industry having been stopped virtually and with increasing landed cost of imported plywood veneers, the jute composite boards provide very good value for the customers without any compromise in properties.

By converting flexible jute materials into rigid/semi-rigid sheet for use in packing as a substitute for wood and plywood suitable jute composite materials/products of market potential like soft packaging for tea and other food packages; crates for fruit packaging and jute-resin bonded intermediate products/materials for various packing purposes were developed.

Wood panels from jute sliver/fibre/fabric with 
thermosetting resin to replace wood and plywood were produced. Resin Transfer Moulded (RTM) products to be used by the automobile sector and jute reinforced Plastic Compoundings to produce various packaging products were developed.

Commercial exploitation of jute reinforced thermoplastic laminates and composites, products developed in substitutio $\mathrm{n}$ for currently utilized thermoplastic and manmade fibre reinforced composites promises great potential with high physical properties and excellent performance at low weights, i.e. high stiffness, high strength and low density.

\section{REFERENCES}

[1] "Fibre-reinforced composites: Materials, Manufacturing, and Design” by Mallick P.K. published on 1988. ISBN 0-8247-7796-4

[2] www.worldjute.com/diversification/diversification_composit e_techno_8.html

[3] www.woodweb.com.

[4] "Investigation on jute fibres and their composites based on polypropylene and epoxy Matrices” Phd thesis by Der Fakultät Maschinenwesen, Technischen Universität Dresden, 2006.

[5] Das S, “Jute composite and its applications”, International workshop IJSG, 2009.

[6] www.jute.org
[7] Mohanty A. K., Misra M. and Hinrichsen G. Biofibers, "biod egradable polymers and biocomposites": Macromolecular Materials and Engineering, 2000 a, 276,1-24.

[8] Samajpati S., Sengupta S., Chattopadhyay S. N., Dey A. and Bhattacharya S. K.: “Jute- based composite products", Asian Textile Journal, July 2005, p70-72

[9] www.tifac.org.in.

[10] Placketta David, Løgstrup Tom Andersenb, Walther Batsberg Pedersenc, Lotte Nielsenc: "Biodegradable composites based on l-polylactide and jute fibres”, Composites Science and Technology 63 (2003) 1287-1296.

[11] Nabi D.S. and Jog J.P.: "Natural fibre polymer composites", Advanced in Polymer Technology, Vol.18, No.4351-363(19 99).

[12] Kathleen V.V., Kiekens P., “Thermoplastic pultrusion of natural fibre reinforced composites”, Composite structures 54 (2001) 355-360.

[13] Singh B., Gupta M., Verma A.: "The durability of jute fibre-reinforced phenolic Composites”, Composites Science and Technology 60 (2000) 581-589.

[14] Ray D, Sarkar B K, Basak R K, Rana A K.” Study of thermal behaviour of alkali treated jute fibres”. J Appl Polym Sci 2002, 85, 2594-2599.

[15] Gassan J, Bledzki A J. "Effect of moisture content on the properties of silanized jute ep oxy”, Polym Composites ,1997, $18,2,179-184$.

[16] Gassan J, Bledzki A K. "Possibilities for improving the mechanical properties of jute/epoxy composites by alkali treatment of fibres”, Composites Science Technology,1999, 59, 1303-1306. 